\title{
Thermal behaviour and kinetics of copper (II) soaps and complexes derived from mustard and soyabean oil
}

\begin{abstract}
TGA technique has been applied to Copper (II) soaps derived from Mustard and Soyabean oils and their complexes, with $\mathrm{N}$ and $\mathrm{S}$ containing ligands, for their thermal analysis and evaluation of energy of activation. Of the six systems studied, three (CM, CMU and CMB) are derived from Mustard oil, and three (CS, CSU and CSB) are derived from Soyabean oil. The results of thermogravimetric analysis reveal that all the referred systems undergo stepwise thermal degradation in three steps corresponding to the decomposition of polyunsaturated, monounsaturated and unsaturated fatty acid components of their corresponding edible oil in the temperature range of $473 \mathrm{~K}-823 \mathrm{~K}$ (2000C-5500C). The energy of activation ' $E$ ' has been evaluated for thermal degradation of each of the three steps for all our referred systems, using various equations like Coats - Redfern, Horowitz - Metzger and Broido equation. It has been observed that for all the equations applied, the stepwise energy of activation follow the order -Step III > Step II $>$ Step I. The general order of activation energies can be represented as - Copper Mustard and Soyabean soap-Urea complex $>$ Copper Mustard and Soyabean soap- 2-amino,6-chloro Benzothiazole complex $>$ Copper Mustard Soap > Copper Soyabean Soap.
\end{abstract}

Keywords: thermal degradation, energy of activation, copper soaps, complexes, mustard oil, soyabean oil, compounds, sulphur, micellar, aldehydes, fungicidal, ketones, nitrogen, lubricants, vegetable oil
Volume 4 Issue 2 - 2017

\author{
Arun Kumar Sharma, Pragya Tank, Rashmi \\ Sharma \\ Department of Chemistry, S.P.C. Govt. College, Ajmer-30500I, \\ Rajasthan, India
}

Correspondence: Rashmi Sharma, Department of Chemistry, S.P.C. Govt. College, Ajmer-30500I, Rajasthan, India, Email sharmaanrun423@gmail.com, avinash_1965@yahoo.co.in

Received: February 16, 2017 | Published: March 10, 2017

\section{Introduction}

Vegetable oil based lubricants are slowly replacing the mineral oils due to their extraordinary biodegradability and many other specific properties. Copper metal as well as nitrogen and sulphur containing compounds play a vital role in fungicidal activities. These facts led us to synthesize Copper soaps of edible oils and their complexes with ligands containing nitrogen and sulphur elements, to study their thermal behaviour, micellar characteristics and to investigate the role of Copper metal in fungicidal activities for exploring their applications and possible uses in various industries and agriculture. Since thermogravimetric methods have been used in characterization of oils and fats; this technique has been employed to study the kinetics of thermal decomposition of soaps and complexes derived from these oils.

Oxidation of the oils, as the principle reaction, occurs through a free radical mechanism i.e. decomposition of hydroxides and peroxides take place in low molecular weight acids and aldehydes. ${ }^{1,2}$ TGA / DTA curves are analysed in order to evaluate the kinetic parameters and the oxidative induction period. ${ }^{3,4}$ Since oxidative thermal decomposition involves exothermic and endothermic reactions, it is possible to estimate the energy of activation involved in the process. Therefore, this method is more advantageous than the conventional method, because it is more precise and sensitive; and require a smaller sample mass and results are obtained more rapidly. ${ }^{5}$

Literature survey reveals that several methods of kinetic analysis, which have been proposed, are based on hypothesis that from single thermogravimetric trace, meaningful values may be obtained for parameters such as activation energy pre-exponential factor and reaction order. $^{6-8}$ Various other scientists have done TGA studies to evaluate various kinetic parameters for metal soaps of transition metals like $\mathrm{Zn},{ }^{9} \mathrm{Cu},{ }^{10,11} \mathrm{Mn}^{12}$ and $\mathrm{Ni}^{13}$ The various kinetic parameters evaluated included rate constants, order of reaction and energy of activation.

\section{Experimental}

Thermogravimetry has been employed to study the kinetics of thermal decomposition of all the soaps and complexes. The soaps and complexes were characterised using ir, NMR and ESR spectral techniques [14]. These oils were also analyzed using GLC to establish their fatty acid composition [15]. The TGA curves of the samples were obtained on Metter - Toledo system (TGA/SDTA 851e) Module. The analysis was done on STARe software system. TGA was done on nitrogen (N2) atmosphere between 500C-7500C at the rate of $100 \mathrm{C}$ per minute. The results were obtained as plots of 'weight loss $\mathrm{v} / \mathrm{s}$ temperature' and '\% weight loss $\mathrm{v} / \mathrm{s}$ temperature'.

The Copper soaps and complexes are abbreviated as follows:-

a. Copper - Mustard soap (CM),

b. Copper - Soyabean soap (CS),

c. Copper - Mustard soap - Urea complex (CMU),

d. Copper - Mustard soap - 2-amino,6-chloro Benzothiazole complex (CMB),

e. Copper - Soyabean soap - Urea complex (CSU),

f. Copper - Soyabean soap - 2-amino,6-chloro Benzothiazole complex (CSB).

\section{Results and Discussion}

\section{Thermal analysis}

Of the six referred systems studied, three (CM, CMU and CMB) are derived from Mustard oil, and three (CS, CSU and CSB) are derived 
from Soyabean oil. The results of thermogravimetric analysis reveal that all the referred systems undergo stepwise thermal degradation in three steps corresponding to the decomposition of polyunsaturated, monounsaturated and unsaturated fatty acid components of their corresponding edible oil. The graphical representation (Figure 1 \& 2) of the three step thermal degradation profiles, where all the referred systems have similar characteristics, where all the nonisothermal TGA curves reveal the three step thermal degradation in the temperature range of $473 \mathrm{~K}-823 \mathrm{~K}$ (2000C-5500C). The Copper soaps and complexes decompose into parent ketones, cupric oxide and carbon dioxide. For all the referred systems, the weight of final residue is observed to be in agreement with the theoretically calculated weight of metal oxide from the molecular formula of the corresponding soap / complex.

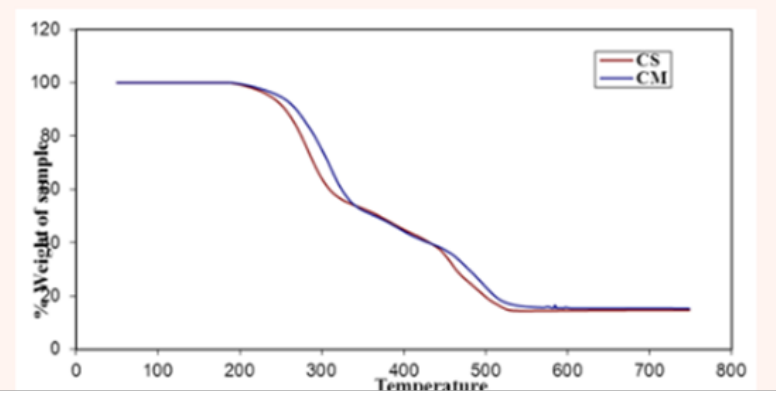

Figure I Plot of \% weight v/s temperature depicting thermal degradation of CM and CS.

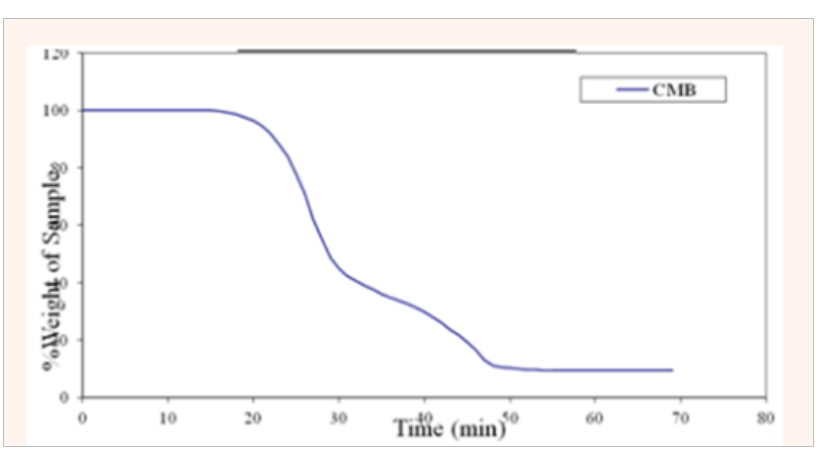

Figure 2 Plot of $\%$ weight $v / s$ time depicting thermal degradation of CMB.

In relation to the thermal decomposition steps, it was observed that the first step ( $473 \mathrm{~K}$ to $623 \mathrm{~K}$ ) corresponds to the decomposition of the polyunsaturated fatty acids. The long chain fatty acids produce volatile compounds, which are constantly removed by vapour generated during heating. These products (dimers, trimers, polymers) are formed principally by thermal reactions of unsaturated fatty acids such as linoleic acids. The first step is the most important for the thermal stability of the soaps/complexes derived from edible oils, because this is the step where decomposition of the unsaturated fatty acids begins.

The second step in the thermal decomposition of soaps derived from edible oils lie in the range of $573 \mathrm{~K}$ to $733 \mathrm{~K}$ (3200C to $4600 \mathrm{C}$ ) and corresponds to the decomposition of monounsaturated fatty acids, such as oleic acid. During this reaction, the double bonds are broken, causing the long chain fatty acid molecules in the edible vegetable oil to become saturated.

The third step in the thermal decomposition, which occurs in the temperature range of $723 \mathrm{~K}$ to $823 \mathrm{~K}$ ( $4500 \mathrm{C}-5500 \mathrm{C}$ ), corresponds to the thermal decomposition of the saturated fatty acids such as palmitic acid. As already mentioned earlier, the weight of the remaining residue is found to be nearly equal to the theoretically calculated weight of cupric oxide.

On comparing CM and CS, it has been observed that they have same thermal stability as the first step thermal decomposition begins at $473 \mathrm{~K}$ in both the cases. An interesting observation noted on perusal of Figure 1 is that the first step for CM lies in the range of $473 \mathrm{~K}$ to $623 \mathrm{~K}$, while CS undergoes first step degradation in the range of $473 \mathrm{~K}$ to $593 \mathrm{~K}$. Hence, the possibility cannot be denied that CM, which is derived from mustard oil, takes longer time and need higher temperature to completely decompose its polyunsaturated fatty acid (PUFA) content as compared to CS, which is derived from soyabean oil.

Similarly, for second step decomposition of CM the range is $623 \mathrm{~K}$ to $733 \mathrm{~K}$, and for CS the range lies between $593 \mathrm{~K}$ and $723 \mathrm{~K}$. Thus again it may be suggested that $\mathrm{CM}$ needs longer time and higher temperature to completely decompose its monounsaturated fatty acid (MUFA) content as compared to CS, which is derived from soyabean oil.

For the third step, for CM the decomposition range lies between $733 \mathrm{~K}$ and $803 \mathrm{~K}$. Therefore, it can be again be suggested that CM needs longer time and higher temperature to completely decompose its saturated fatty acid content as compared to CS. Thus, the possibility cannot be denied that $\mathrm{CM}$ possesses higher thermal stability in comparison to $\mathrm{CS}$

The thermal decomposition of Urea complexes i.e. CMU and CSU derived from mustard oil and soyabean oil also occurred in three stages corresponding to the decomposition of polyunsaturated, monounsaturated and saturated fatty acid components respectively, and each complex has three decomposition steps in the range of 533K to $823 \mathrm{~K}$ ( $2600 \mathrm{C}$ to $5500 \mathrm{C}$ ). The first, second and third step of each complex lie in the range of $533-633 \mathrm{~K}, 633-733 \mathrm{~K}$ and $733-823 \mathrm{~K}$ respectively.

On the basis of the temperature at the beginning of thermal decomposition, it can be established that Urea complexes have a higher thermal stability than their corresponding soaps. Thus it can be suggested that thermal stability is influenced by the presence of ligand.

The results of thermogravimetric analysis of 2-amino,6-chloro Benzothiazole complexes CMB and CSB are similar to those observed for previous systems. Obviously, the decomposition of the complex is a bit slow in the beginning and the weight loss is small. The plots of ' $\%$ weight verses time, and versus temperature; are of identical nature; the pyrolytic curves indicate that decomposition is fairly rapid as the temperature increases with time. The TGA curve plotted for CMB and CSB depict that the decomposition of the complex takes place in three steps, in temperature range of $493 \mathrm{~K}$ to $803 \mathrm{~K}$ ( $2200 \mathrm{C}$ to $5300 \mathrm{C}$ ). The thermal decomposition of the CMB and CSB, derived from Mustard oil and Soyabean oil occurred in three stages corresponding to the decomposition of polyunsaturated, monounsaturated and unsaturated fatty acid components respectively. The first, second and third step of each complex lie in the temperature range $493-623 \mathrm{~K}, 623-713 \mathrm{~K}$ and 713-803K respectively.

The thermal degradation of the first step of soap and 2-amino,6chloro Benzothiazole complexes begins at $473 \mathrm{~K}$ and $493 \mathrm{~K}$ respectively. On this basis, it may be suggested that thermal stability of complexes is higher than that of soaps. On the basis of the temperature at the beginning of thermal decomposition i.e. initial temperature of step-I, it is clear from Figure $1 \& 2$ that the thermal stability is highest 
for Urea complexes and least for soaps; their thermal stability is in the following order - Urea complex $>2$-amino,6-chloro Benzothiazole complex $>$ Soap.

The higher stability of Urea complex may be ascribed to the fact that Urea ligand being smaller than 2-amino,6-chloro Benzothiazole moiety, fits more compactly within the soap moiety on complexation, resulting in a compact structure which is harder to break.

\section{Kinetic parameters}

These results have been applied on various equations like Coats Redfern [16] equation, Horowitz - Metzger [17] equation and Broido [18] equation to evaluate the energy of activation (E) for thermal degradation of each of the three steps of these systems. Of the various methods of kinetic analysis, Coats - Redfern equation has been found to be the most appropriate in calculating the energy of activation. Coats and Redfern derived the equation

$$
\log f(\alpha) T 2=\log A R a E(1-2 R T E)-E 2.303 R T
$$

Where ' $a$ ' is the linear rate of heating and $f(a)=-\log (1-a)$ for $\mathrm{n}=1$.

Hence, this equation can be rewritten as -

$$
\log \left[\frac{-\log (1-\alpha)}{T^{2}}\right]=\log \frac{A R}{a E}\left(1-\frac{2 R T}{E}\right)-\frac{E}{2.303 R T}
$$

Where 'a' stands for the fraction of soap decomposed, ' $n$ ' for the order of the reaction, ' $K$ ' for the rate constant, ' $E$ ' for the energy of activation of the reaction, ' $\mathrm{R}$ ' the gas constant $(\mathrm{R}=8.314 \mathrm{~J}$ mol-1 $\mathrm{K})$ and ' $\mathrm{A}$ ' for the pre - exponential or frequency factor and is usually assigned to be independent of absolute temperature ' $T$ '.

The values of energy of activation using Coats-Redfern equation for each of the three steps for all the referred systems have been evaluated from the linear plots of $\log \left\{[-\log (1-a)] / T^{2}\right\} v / s \quad 1 / T$ are observed to be in following order:- Step III $>$ Step II $>$ Step I.

Mention may also be made of the fact that although decomposition of all soaps and complexes is continuous with respect to time and temperature, yet Freeman - Caroll method is not applicable, as the plots of $[\log (d w / d t)] /\left[\log W_{r}\right] v / s 1 / T$ order of reaction is not zero.

To confirm the energy of activation, Horowitz - Metzger equation has been used to evaluate the value of ' $E$ ' according to the following equation

$$
\operatorname{In}\left[\operatorname{In}(1-\alpha)^{-1}\right]=\frac{E}{R T_{S}^{2}} . \theta
$$

Where ' $a$ ' is the fraction of soap decomposed at time ' $t$ ', 'Ts' is the temperature at which the rate of decomposition is maximum and ' $\mathrm{q}$ ' is equal to (T-Ts). The energy of activation as recorded in Table 1 are obtained from the slope of the plot between

$$
\ln [\ln (1-a)-1] v / s q
$$

For Horowitz - Metzger equation the values of each step are in the order- Step III $>$ Step II $>$ Step I.

The energy of activation for the stepwise thermal decomposition of all the referred systems has also been calculated by using Broido's equation which is as follows -

$$
\operatorname{In}[\operatorname{In}(1 / y)]=-\frac{E+C}{R T}
$$

Where ' $y$ ' is fraction of weight at temperature ' $T$ ', ' $E$ ' is the activation energy and ' $R$ ' is the gas constant in joule mol-1 K-1. The energy of activation for each step is calculated from the slope of plot between $\ln [\ln (1 / y)]$ and $(1 / T)$. The values of activation energies for different steps of thermal decomposition of all soaps and complexes are recorded in Table 1 and are found to be in the following order.

Step III $>$ Step II $>$ Step I.

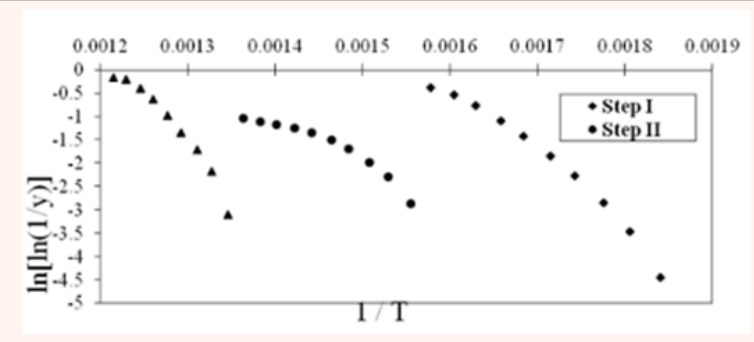

Figure 3 Plot for broido Equation for CMU for different steps.

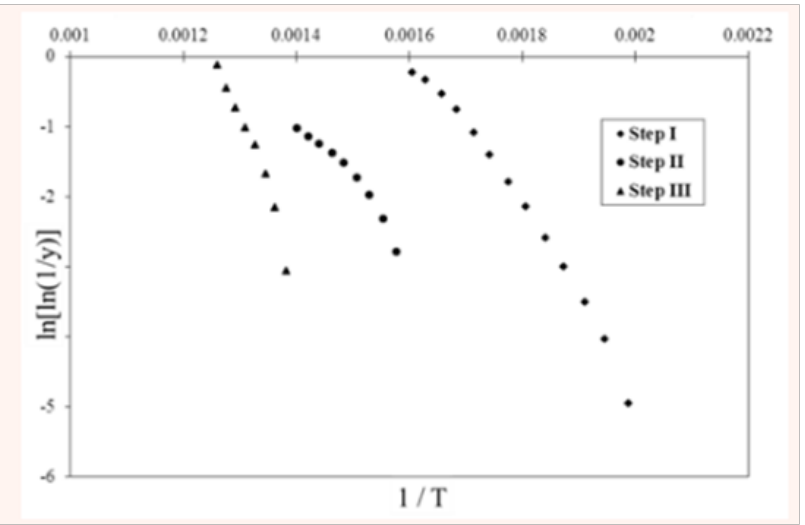

Figure 4 Plot for broido Equation for CMB for different steps.

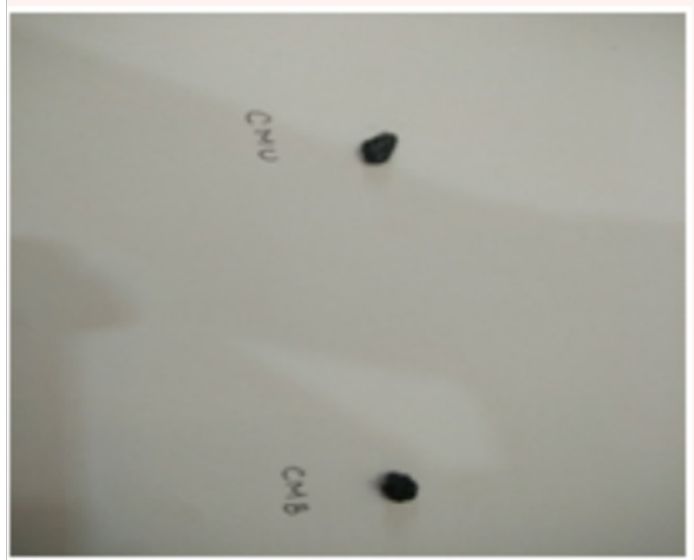

Figure 5 Digital pic of CMB and CMU complexes.

A perusal of Table 1 reveals that for all the referred systems, the value of activation energy is highest for the third step and smallest for the first step, irrespective of the equation applied signifying that saturated fatty acids require highest activation energy for decomposition i.e. the stepwise energy of activation follows the order - Step III $>$ Step II $>$ Step I. It has also been observed that in 
general, the activation energies for the complexes are higher than their corresponding soaps. On studying Table 1 with a comparative overview, it has been observed that Urea complexes, in general, have the highest value of energy of activation and the soaps have the least. The general order of activation energies can be represented as:

Copper Mustard and Soyabean soap-Urea complex > Copper Mustardand Soyabean soap- 2-amino,6-chloro Benzothiazole complex > Copper Mustard Soap > Copper Soyabean Soap.
The Figure $3 \& 4$ depicting broido equation for all three steps of degradation of CMU and CMB respectively. There was a good correlation between the activation energies evaluated by various integration and approximation methods, however, the values obtained by the approximation methods were higher than the values obtained by integration methods, which can be ascribed to the different mathematical treatments of the methods ${ }^{1}$ (Figure 5).

Table I Energy of Activation (In Kj Mole-I) for the decomposition reaction of copper soaps and complexes derived from mustard and soyabean oil using various equations for different steps

\begin{tabular}{|c|c|c|c|c|c|c|c|c|c|}
\hline \multirow{2}{*}{$\begin{array}{l}\text { Complex } \\
\text { ®Step and } \\
\text { Equation }\end{array}$} & \multicolumn{3}{|c|}{ Coats - Redfern } & \multicolumn{3}{|c|}{ Horowitz - Metzger } & \multicolumn{3}{|l|}{ Broido } \\
\hline & I & II & III & I & II & III & $\mathbf{I}$ & II & III \\
\hline CM & 77.325 & 98.414 & 251.306 & 100.975 & 110.795 & 238.435 & 91.454 & $|24.7|$ & $17 \mid .476$ \\
\hline CMU & II 2.867 & 126.145 & 214.448 & II 2.020 & 124.032 & 188.859 & 93.117 & 105.815 & 232.792 \\
\hline CMB & 95.736 & | II.69| & 167.537 & 100.975 & 104.144 & 149.976 & 124.710 & 152.423 & 171.476 \\
\hline CS & 85.098 & 102.118 & 170.107 & 99.335 & 103.787 & 121.438 & 88.031 & 106.894 & 166.28 \\
\hline CSU & 112.867 & 134.030 & I 78.707 & 108.196 & 133.316 & 188.858 & 130.649 & 152.423 & 203.231 \\
\hline CSB & 88.897 & 103.714 & 138.285 & II7.804 & 129.138 & $23|.78|$ & 97.986 & 124.710 & 228.635 \\
\hline
\end{tabular}

\section{Conclusion}

Thermoanalytic and kinetic properties of soaps and complexes are dependent on the composition of fatty acids i.e. the edible oil they are derived from, and the presence of the ligand. The increase in activation energy in relation to the steps in thermal decomposition of the systems studied, occurred due to the possible break in the molecular bonds of unsaturated fatty acids, which are less stable than the molecular bonds of stable saturated fatty acids requiring higher activation energy for degradation. ${ }^{1}$ Also the thermal stability as well as the energy of activation is the highest for Urea complexes and least for the soaps.

\section{Acknowledgements}

The authors are thankful to UGC - CSIR for financial assistance and Principal and Head for laboratory facilities. We are also thankful to Dr. V. P. Mehta and Dr. S. L. Oswal for valuable discussions.

\section{Conflicts of Interest}

The authors do not have any personal or financial interests.

\section{Funding}

None.

\section{References}

1. Souza AG, Santos JCO, Conceicao MM, Dantas Silva MC, Prasad S (2004) A Thermoanalytic and Kinetic Study of Sunflower Oil. Brazilian Journal of Chemical Engineering. 2004; 21(2):265-281.

2. Gennaro L, Bocca AP, Modesti D, et al. Effect of Biophenols on Olive Oil Stability Evaluated by Thermogravimetric Analysis. Journal of Agricultural \& Food Chemistry. 1998;46(11):4465-4469.

3. Santos JCO, Santos AV, Souza AG. Thermal Analysis in Quality Control of the Olive Oil. Europ J Pharm. 2001;13(Supp 1): S23-S24.

4. Santos JCO, Santos AV, Souza AG, et al. Thermal Stability and Kinetic Study on Thermal Decomposition of Commercial Edible Oils by Thermogravimetry. Journal of Food Science. 2002;67(4):1393-1398.
5. Santos JCO, Santos MG, Conceicao MM, et al. Thermoanalytical, kinetic and rheological parameters of commercial edible vegetable oils. Journal of Thermal Analysis and Calorimetry. 2004;75(2):419-428.

6. Nami Shahab AA, Siddiqi KS, Chebude Y. Indian J Chem. 2006;45A:1139-1143.

7. Patel S, Patel A. Indian J Chem. 2002;41A: 528-531.

8. Moharana SC, Praharaj J, Bhatta D. Indian J Chem. 2002;41A:15691574.

9. Rasheed A, Bhobe RA. J Indian Chem Soc. 1976; pp. 442-445.

10. Mehrotra KN, Mehta VP, Nagar TN. Kinetics of Thermal Decomposition of Copper Soaps. Z Naturforsch. 1973;28b: 90-92.

11. Mehrotra KN, Saroha SPS, Kachhwaha R. Tenside Det. 1981;18(1):2830.

12. Varma RP, Kedar Singh. Application of thermogravimetric equations in the thermal decomposition of manganese (II) soaps. Transition Metal Chemistry. 1980;5(1):39-42.

13. Mehrotra KN, Kachhwaha RN. Tenside Det. 1980;7(6):304-306.

14. Sharma R, Tank P, Saxena M, et al. Synthesis and Characterisation of Antifungal Agents Containing Copper(II) Soaps and Derived from Mustard and Soyabean Oil. Tenside Surf Det. 2008;45(2):87-92.

15. Sharma R, Bhutra R, Acharya S, et al. European Journal of Lipid Science and Technology. 2007;39(3):111-113.

16. Coats AW, Redfern JP. Kinetic Parameters from Thermogravimetric Data. Nature. 1964;201(4914):68-69.

17. Horowitz HH, Metzger G. A New Analysis of Thermogravimetric Traces. Analytical Chemistry. 1963;35(10):1464-1468.

18. Broido A. A simple, sensitive graphical method of treating thermogravimetric analysis data. Journal of Polymer Science. $1969 ; 7(7): 1761-1773$ 